PERCEPTION OF UNDERGRADUATE PHYSIOTHERAPY STUDENTS TOWARDS CLINICAL ATTRIBUTES \& CLINICAL TEACHING

\author{
Omkr Samant *, G.D. Vishnu Vardhan.
}

Dr. A.P.J. Abdul Kalam College of Physiotherapy, Pravara Institute of Medical Sciences, Loni BK, Maharashtra, India.

\title{
ABSTRACT
}

Background: Physiotherapists work in a health care situation of constant rising complexity and rapid change and demands for accountability, of careful examination from both internal and external sources. In such situations, the ability to respond appropriately to these pressures is critical, not only for professional growth but also for professional survival. New generations of emerging physiotherapists require more than a solid foundation of clinical skills. They require a proper educational foundation that is reinforced with good attributes, attitude and skills that will help them in building their profession as well as their professional practice. Clinical Teaching is very important in preparing Physiotherapists for working with patients and it has long been recognized as a necessary part of Physiotherapy education.

Context \& Purpose of the study: The present study included 200 participants from $1^{\text {st }}$ year there were around 52 students with average score of $106.63,2^{\text {nd }}$ year with around 55 students with average score of $106.13,3^{\text {rd }}$ year with around 22 students with average score of $107.9,4^{\text {th }}$ year with 71 students with average score of 104.39.

Results: The result shows mean value of 105.75 and SD value of 12.80654 . The result concluded that the Perception of Undergraduate Physiotherapy Students towards Clinical Attributes and Clinical Teaching is Good according to the gradings.

Conclusion: The present study concluded that the Perception of Undergraduate Physiotherapy Students of Dr. A. P. J. Abdul Kalam College of Physiotherapy is Good. Overall, Undergraduate Physiotherapy Students rated the clinical teaching attributes of their teachers highly, and they were also satisfied and felt positively challenged during their clinical rotations.

KEY WORDS: Perception, Clinical Attributes, Clinical Teaching, Undergraduate Students.

Address for correspondence: Dr. Omkr Samant. PT., Dr. A.P.J. Abdul Kalam College of Physiotherapy, Pravara Institute of Medical Sciences, Loni BK, Maharashtra, India.

Contact No: 8830284698 E-Mail: dromkr.physio@gmail.com

Access this Article online

Quick Response code

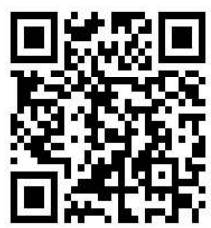

DOI: $10.16965 /$ ijpr.2020.185

Journal Information

\section{International Journal of Physiotherapy and Research}

ISSN (E) 2321-1822 | ISSN (P) 2321-8975 https://www.ijmhr.org/ijpr.html

DOI-Prefix: https://dx.doi.org/10.16965/ijpr

(cc) ET-Ne-Bh

Article Information

Received: 11 Nov 2020

Peer Review: 11 Nov 2020

Revised: None
Accepted: 30 Nov 2020

Published (O): 11 Dec 2020

Published (P): 11 Dec 2020

\section{INTRODUCTION}

Physiotherapists work in a health care situation of constant rising complexity and rapid change and demands for accountability, of careful examination from both internal and external sources.

Clinical Teaching is very important in preparing Physiotherapists for working with patients and it has long been recognized as a necessary part of Physiotherapy. Clinical Teaching consists of both affective and psychomotor learning objectives. Clinical Teaching occurs in a setting in which administrators, directors and most importantly, teachers are willing to provide it.

In India, the number of Physiotherapy colleges 
have increased recently, most of the Physiotherapy institutes have agreement of understanding signed with various hospitals for clinical teaching and training.

In addition, nowadays Physiotherapists work with individuals to prevent the loss of mobility before it occurs by developing fitness programs and well oriented programs, to develop, maintain and restore maximum movement and functional ability throughout the life. The amount of clinical experiences that a student can have is tremendous.

Theory and skills taught in the Physiotherapy colleges may be actually a patient problem orientation, but students rarely, if ever, learn the clinical context until their first clinical experience.

There is overwhelming agreement in the literature regarding the value and importance of clinical teaching in Physiotherapy.

Clinical teaching is enhanced by interactions, teachers can yield information on matters learned in a classroom lecture, a text, or a previous clinical teaching experience that provides the clinical teacher with an understanding of the gaps in the essential knowledge of the student.

Problem solving and clinical decision making are challenging that the student progressively takes. In India, still the concept of diagnosis before the thought of which modality is to be used to treat is yet to be engrained in the mindset of many physiotherapists.

Clinical teachers play a vital role in the clinical teaching of undergraduate physiotherapy students. The characteristics of an ideal clinical teacher as perceived by the students have been reported to be professionalism, being a role model for the students, describing the decision-making process, considering the self-respect of students, willingly helping the students, appropriate knowledge of the respective subject and ability to demonstrate and convey that knowledge to the students.

The most important and most hindering behaviours of clinical teachers that students think a clinical teacher must possess have been found to be focusing on practical learning of technical skills, treating students in a friendly manner and teaching with enthusiasm. Most commonly reported teaching behaviours that limit learning are asking questions in a rude way that discourages the students, error correction of students in front of patients, not recognizing extra efforts of the students and not allocating proper time for teaching.

There has been no research done in India on clinical attributes and clinical teaching in physiotherapy students. No current researchbased evidence is available. The evaluation is especially important to get better outcomes in clinical attributes and clinical teaching. An improvement in clinical attributes and clinical teaching in India can be achieved only if proper evaluation is done. It is especially important to find out the perception of undergraduate physiotherapy students regarding their clinical instructors their attributes and clinical teaching.

According to Duncan [1], student learning could be maximized if a student is first inspired by the teacher, then provided with motivation and then taught. However, clinical teaching is believed to be different from the traditional classroom teaching because it requires key attributes including one-to-one evaluation and small group management skills [2].

Bench [3] has described three versions of physiotherapy clinical education organization. The internal version is one in which both the foundational and clinical sciences theory and students' clinical experience are provided in the same institution. This insular training mode typically based in hospitals existed during the early stage in the development of physiotherapy as a profession and no longer exists today. In an external version now prevalent in the USA, student's affiliation experiences take place in free-standing hospitals, clinics, and centres.

Important clinical teaching behaviours identified among physiotherapist teachers include offering opportunities to practice technical and problem-solving skills, friendliness and positive regard towards students, showing enthusiasm for teaching and sensitivity to patients' needs [4,5]. Asking questions in an intimidating manner, correcting students in front of patients, basing judgement on 
indirect evidence, not recognizing extra effort, after hour unavailability, and not setting time limits for teaching activities were identified as hindering behaviors [5]. However, previous studies on physiotherapy clinical instruction were limited to developing theories and models on clinical education and were conducted in a few developed countries [5-9].

From the literature, an ideal clinical education experience is one that takes place in a learning atmosphere that allows for establishing a mutually beneficial student-supervisor relationship. Maximized learning following clinical instruction is deemed best achievable if the teachers have formal preparation on teaching. Furthermore, the extant literature shows that a desirable clinical experience is one that can facilitate the connection between theory and practice [10] and is subjected to ongoing peer evaluation for quality improvement [7]. Involving students in a humanistic and rigorous approach to practice and being a professional that students would want to emulate, were associated with a positive perception of effective teachers.

Students perspectives on clinical teaching attributes can contribute to knowledge on teaching and learning in clinical education and represent consumers input that could improve teaching quality. Feedback on clinical teaching obtained from students have the potential benefits of improving the effectiveness of teachers [11,12].

The term academician or clinical teacher, in this study, is used to describe a university employed physiotherapist who teaches foundational and clinical courses and also provides clinical instruction to students during rotations. The term clinician as used in the present study refers to a physiotherapist employed by a teaching hospital and who provides clinical instruction to students [13]. This study is the first attempt at assessing clinical attributes \& clinical teaching in physiotherapy education in India. The objective of the study was to report on students perceptions of the clinical teaching skills of their teachers and their clinical attributes. It is a self-administered tool. It can be used worldwide by different Physiotherapy colleges to determine the perception of the undergraduate students towards the clinical attributes and clinical teaching. It can also help to determine the clinical attributes of the teacher as well as the clinical teaching technique.

The main purpose is to determine the Perception of Undergraduate Physiotherapy Students towards the clinical attributes and clinical teaching and change the things that negatively affects the learning process for the students.

The benefits of the study is determining the perception of the students which will help to change the techniques that affects the learning process. It will also help to know the way in which the teachers treat the students whether asking answers rudely will demotivate the students or negatively affects the learning process of the students.

The study was to use this insight to develop a set of statements about teaching and learning, grounded in clinical teachers and students perceptions of their roles within the clinical teaching. If teachers and students share similar or have an awareness of each-others conceptions of the goals of clinical education and professional identities, then the education process is likely to be more effective. Also, there should be recognition of the best teachers according to the students who are best at their clinical teaching and their attributes. By recognizing such teachers their kind of teaching methods can be used in order to facilitate the learning process. As rude behaviour from the teachers can lead to students lack of interest in any particular subject or the whole course which can negatively affect the students.

It will also help contribute to knowledge on teaching and learning in clinical education and represent input that could improve teaching quality and effectiveness of the teachers.

\section{METHODS}

Study setting: Dr. A.P.J Abdul Kalam College of Physiotherapy, Pravara Institute of Medical Sciences, Loni BK, Maharashtra.

Sample Size: 200

Sampling method: Purposive Sampling 
Study Duration: 6 months

Study Design: Observational Cross-Sectional Study

Materials to Be Used:

- Consent form

- Data collection sheet

- Omkr's Empirical Clinical Evaluation Tool

Outcome measure: Omkr's Empirical Clinical Evaluation Tool instrument will be used to evaluate the teaching attributes of clinical teachers by determining the Perception of Undergraduate Physiotherapy Students. This is developed to evaluate the clinical teaching attributes of the teachers \& has been recently validated to be used for physiotherapy clinical teaching.

5 Pointer Likert Scale:

It is used with response options ranging from 1 to 5 ,

1- Strongly Disagree

2- Disagree

3- Neutral

4- Agree

5- Strongly Agree

Grades:

28 - 80: Very Low

81- 100: Low

101 - 120: Moderate

121 - 140: High

These grades can be used to determine the whether the perception is very low or high just by comparing the scores of the students.

The total possible minimum score is 28 and the maximum possible score is 140 .

The higher the total agreement score, the better the assessment rating on the attributes.

Omkr's empirical clinical evaluation tool:

1. Approximately how often have you attended the classes this year?

2. Approximately how many hours per week did you dedicate to study?

3. The teachers had reasonable learning expectations from you.

4. The teachers have high quality/good clinical teaching skills.
5. The teachers covered all the key points of the current syllabus.

6. The teachers include current development and recent advances in their teaching.

7. The teaching techniques are easier to understand.

8. The assignments were helpful for my learning.

9. The teacher provided adequate opportunities to clarify the questions during class time, considering the size of the class.

10. The atmosphere in the classroom was excellent for learning.

11. The teachers show respect for individual differences (e.g., disabilities, gender, race, religion, sexual orientation).

12. The teacher was available to help students academically, whether in person, by email, or via online meeting.

13. The physical facilities (e.g., classroom, furnishings) were appropriate.

14. The teacher encourages you to express your doubts and opinion.

15. The teachers encourages students to take responsibility for their own learning.

16. The teacher is usually well prepared for teaching sessions.

17. The teachers emphasizes concepts rather than factual recall.

18. As Physiotherapy is a patient oriented program, the teachers emphasizes clinical skills, rather than theory lectures.

19. There is a need of interactive session rather than just providing answers?

20. The teacher demonstrates patient documentation, evaluation, treatment.

21. The teacher observes clinical practice of student and comments.

22. As the students demonstrates clinical practice, the teacher helps by facilitating the process.

23. The teacher allows you to observe peers during clinical practice if facing any difficulty in learning.

24. The student participates in small-group discussion on patient management. 
25. The student participates in a ward round i.e. the ward round included in the clinical postings.

26. The student is assessed by other students on patient management.

27 . The teachers motivate you to assess your own learning.

28. The student and teacher plan learning activities together.

29. The teachers incorporated in engaging and fun learning activities.

30. The teacher is clear and understandable in his/her explanations.

\section{Feedback questions:}

1. If you could change one thing about this classroom, what would you change and why? (Comments only)

2. Which teacher should be acknowledged for their excellent teaching. In your comments, explain why.

3. Identify one thing the teacher should continue doing to facilitate your learning. (comments only)

4. Identify one thing the teacher does that negatively affects your learning and should therefore stop doing. (comments only)

5. Identify one thing the teachers should start doing to facilitate your learning. (comments only)

\section{Inclusion Criteria:}

1- Male and Female students.

2- Undergraduate physiotherapy students from 1 st year to 4 th year.

3- Written Informed consent form from the participants.

\section{Exclusion Criteria:}

1- Students whose parents were from the medical profession.

2- Students who were doing honorary internships apart from the supervised clinical practice provided by their institutes were excluded from the study.

Procedure: The Omkr's Empirical Clinical Evaluation Tool questionnaire will be used to examine attributes of effective clinical teaching in this study.
Omkr's Empirical Clinical Evaluation Tool instrument will be used to evaluate the teaching attributes of clinical teachers by determining the Perception of Undergraduate Physiotherapy Students. This is developed to evaluate the clinical teaching attributes of the teachers \& has been recently validated to be used for physiotherapy clinical teaching.

5 Point Likert Scale:

It is used with response options ranging from 1 to 5 ,

\section{1- Strongly Disagree}

2- Disagree

3- Neutral

4- Agree

5- Strongly Agree

The questionnaire will be given to the students online i.e. through Google Forms.

A 30-point questionnaire \& 5 feedback questions for the study will be given to the students. It is MCQ type questionnaire in which the students will be able to answer from scale 1 to 5 i.e. from strongly disagree to strongly agree.

The survey questionnaire consists of four parts:

Part I: elicited socio-demographic information including name, date, Participants consent form i.e. their name and signatures.

Part II: Respondents will complete Omkr's Empirical Clinical Evaluation Tool. The tool has 30 attributes with a Likert scale from "strongly disagree" to "strongly agree".

Part III: The respondents indicated the level of importance they attach to the attributes as a measure of effective clinical teaching on a Likert scale from "strongly disagree" to "strongly agree".

Part IV: 5 feedback questions have been given to answer. Feedback question are to determine what all things should be changed or acknowledged and also what things facilitate your learning or negatively affects your learning.

The total possible minimum score is 28 and the maximum possible score is 140 . The higher the total agreement score, the better the selfassessment rating on the attributes. 
Physiotherapy students in the professional phase of their training as well as their clinical teachers (academic and clinical faculty) will be surveyed in Dr. APJ Abdul Kalam College of Physiotherapy, Pravara Institute of Medical Sciences, Loni.

Participants will be informed accompanying the questionnaires that completion of the questionnaires implied consent to participate, and that anonymity will be assured. No form of identification will be required on the questionnaire which takes about 20 minutes to complete.

The Omkr's Empirical Clinical Evaluation Tool is selected over other instruments for determining attributes of effective clinical teachers because of its clarity, brevity, ease of application and its summative value.

The main aim of providing the questionnaire through Google Forms is to maintain privacy and confidentiality.

Inference: The result shows mean value of 105.75 and SD value of 12.80654 . The result concluded that the Perception of Undergraduate Physiotherapy Students towards Clinical Attributes and Clinical Teaching is Good according to the gradings.

Table 1: No. of students and their average score according to every year.

\begin{tabular}{ccc}
\hline Year & Avg & No of students \\
\hline $\mathbf{1}^{\text {st }}$ & 106.63 & 52 \\
$\mathbf{2}^{\text {nd }}$ & 106.13 & 55 \\
$\mathbf{3}^{\text {rd }}$ & 107.9 & 22 \\
$\mathbf{4}^{\text {th }}$ & 104.39 & 71 \\
\hline
\end{tabular}

Graph 1: Represents the data.

Average score and number of students year wise

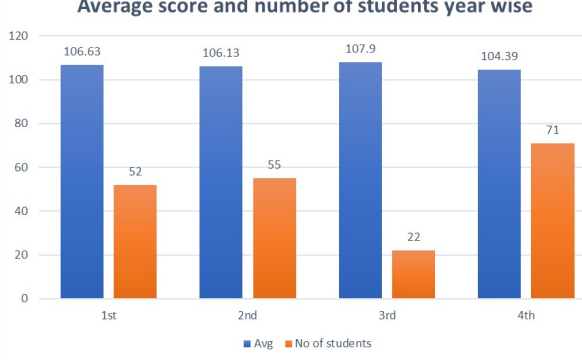

Table 2: Tabular representation of the participants.

\begin{tabular}{cccccc}
\hline & 1st Year & 2nd Year & 3rd Year & 4th Year & Total \\
\hline $\mathbf{2 8 - 8 0}$ & 0 & 0 & 0 & 4 & 4 \\
$\mathbf{8 1 - 1 0 0}$ & 17 & 24 & 8 & 26 & 75 \\
\hline $\mathbf{1 0 1 - 1 2 0}$ & 33 & 7 & 12 & 30 & 82 \\
\hline $\mathbf{1 2 1}-140$ & 2 & 24 & 2 & 11 & 39 \\
\hline Total & 52 & 55 & 22 & 71 & 200 \\
\hline
\end{tabular}

Int J Physiother Res 2020;8(6):3715-22. ISSN 2321-1822

Graph 2: Graphical representation of participants.

Grades Year Wise

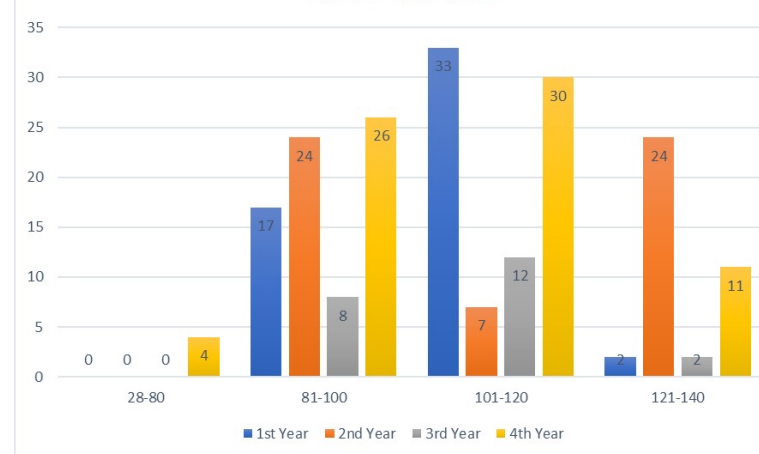

\section{RESULTS AND DISCUSSION}

The aim of the study was to study the Perception of Undergraduate Physiotherapy Students towards clinical attributes and clinical teaching.

The perception of the students which will help to change the techniques that affects the learning process. It will also help to know the way in which the teachers treat the students whether asking answers rudely will demotivate the students or negatively affects the learning process of the students.

The Omkr's Empirical Clinical Evaluation Tool is selected over other instruments for determining attributes of effective clinical teachers because of its clarity, brevity, ease of application and its summative value.

Clinical teaching is the essence of all physiotherapy education because clinical education is the way by which clinical teachers facilitate students to acquire knowledge and skills in the real practical setting to become competent and skilled. Clinical Teachers plays an important role because they provide students with an opportunity to achieve competency, selfconfidence, professional identity, professional attitudes, and proficiency in their profession.

The present study included 200 participants from 1st year there were around 52 students with average score of 106.63, 2nd year with around 55 students with average score of 106.13 , 3rd year with around 22 students with average score of 107.9 , 4th year with 71 students with average score of 104.39. The result shows mean value of 105.75 and SD value of 12.80654 . The result concluded that 
the Perception of Undergraduate Physiotherapy Students is Good according to the gradings.

The result concluded that the present study was significant. By using Omkrs Empirical Clinical Evaluation Tool the results were the perception of undergraduate physiotherapy students of Dr. A. P J. Abdul Kalam College of Physiotherapy towards clinical attributes and clinical teaching is Good i.e. more than half of the students were satisfied with their clinical attributes and clinical teaching of their teachers. The existence of good interpersonal relationship with teachers could ease students' anxiety during clinical rounds. The value of a mentor-mentee relationship which facilitates interpersonal relationship may be well appreciated by both the teachers and the students.

Clinical education is very important in preparing the students for the practical field. This study is the first step towards the assessment of an important aspect of clinical education in India. Analysing the effectiveness of the strategies used by the clinical teachers is a key element of clinical education.

An important underlying premise of the study was that both clinical teachers and students' perceptions of teaching and learning influence the way they approach and adapt to the teaching and learning requirements of the clinical placement settings, and provides one representation of their conception of teaching and learning.

Clinical Teaching is very important in preparing Physiotherapists for working with patients and it has long been recognized as a necessary part of Physiotherapy education.

Clinical Teaching consists of both affective and psychomotor learning objectives. Clinical Teaching occurs in a setting in which administrators, directors and most importantly, Physiotherapy teachers are willing to provide it.

By using Omkrs Empirical Clinical Evaluation Tool the results were the perception of undergraduate physiotherapy students of Dr. A. P J. Abdul Kalam College of Physiotherapy towards clinical attributes and clinical teaching is moderate i.e. more than half of the students were satisfied with their clinical attributes and clinical teaching of their teachers.

Omkrs Empirical Clinical Evaluation Tool used to evaluate the teaching attributes of clinical teachers by determining the Perception of Undergraduate Physiotherapy Students towards clinical attributes and clinical teaching. This tool was recently developed and validated to be used for physiotherapy clinical teaching. There all $30 \mathrm{MCQ}$ type questions \& 5 feedback questions which has 5 Pointer Likert Scale ranging from 1 to 5, i.e. from strongly disagree to strongly agree and has a grading system i.e. $28-80$ : Very Low, 81 - 100: Low, 101 - 120: Moderate, 121 - 140: High. The table number 1 shows the number of students and their average score according to every year so from 1 st year 52 students participated in this research and their average score was 106.63, from 2nd year there were 55 students with average score 106.13, from 3rd year there were about 22 students with average score of 107.9 , from 4 th year there were around 71 students with average score of 104.39 .The table no. 2 graphical presentation of the participants according to the grades. 0 students from 1st year, 2nd year \& 3 rd year graded from $28-80$, only 4 students from final year graded from $28-80$ i.e. in all only 4 students graded from $28-80$. 17 students from 1st year, 24 students from 2nd year, 8 students from 3rd year, 26 students from 4th year graded from $81-100.33$ students from 1 st year, 7 students from 2 nd year, 12 students from 3 rd year and 30 students from 4th year graded between 101 - 120.2 students from 1st year, 24 students from 2 nd year, 2 students from 3 rd year \& 11 students from 4 th year graded between $121-140$.

There were 5 feedback questions which were given to get a proper feedback regarding the teaching techniques, about the classrooms, about the teacher they should be acknowledged, also about the things that facilitate and negatively affects the learning process.

When asked about the one change that the students want to change about Teaching many students suggested that there should be more practical sessions as the practical knowledge 
will help them solve their theoretical queries. Some also suggested to switch ppt based learning to seminars and interactive sessions which would be more helpful. Also, the partiality between the clever students and the average students was mentioned this should be avoided. Due to increase in the number of students in a particular class it was suggested there should be proper mic system. When asked about one thing that teachers should continue to facilitate your learning majority of the participants suggested there should be more of the practical session to facilitate learning. It was also suggested to give more importance to practical knowledge rather than theoretical knowledge. When asked about things that teachers do that negatively affects learning majority participants suggested inadequate time for practical's negatively affects the learning process. Also pointing out someone and insulting them in front of the whole class also negatively affects the students and also the learning processes. Pointing out average students and helping their favourites also negatively affects the learning process.

\section{CONCLUSION}

The present study concluded that the Perception of Undergraduate Physiotherapy Students of Dr. A. P. J. Abdul Kalam College of Physiotherapy is Good according to the gradings. Overall, Undergraduate Physiotherapy Students rated the clinical teaching attributes of their teachers highly, and they were also satisfied and felt positively challenged during their clinical rotations.

\section{Conflicts of interest: None}

\section{REFERENCES}

[1]. Duncan PW. One grip a little stronger. Phys Ther 2003;83:1114-1122.

https://doi.org/10.1093/ptj/83.11.1014

[2]. Knox JE, Morgan J. Important clinical teachers behaviour as perceived by university faculty, students and graduates. J Adv Nurs 1985;10:25-30.

https://doi.org/10.1111/j.1365-2648.1985.tb00488.x PMid:3844410
[3]. Bench J. On organizational model of clinical education. J Allied Health 1999;28:179-183.

[4]. Emery M. Effectiveness of the clinical instructor: students' perspective. Phys Ther 1984;64:10791083.

https://doi.org/10.1093/ptj/64.7.1079 PMid:6739551

[5]. Jarski RW, Kulig K, Olson RE. Clinical teaching in physical therapy: student and teacher perceptions. Phys Ther 1990;70:173-176.

https://doi.org/10.1093/ptj/70.3.173 PMid:2304975

[6]. Onuoha AR. Effective clinical teaching behavious from the perspectives of the students, supervisors and teachers. Physiotherapy 1994; 80:208-214. https://doi.org/10.1016/S0031-9406(10)61298-9

[7]. Cross V. The professional development diary: a case study of one cohort of physiotherapy students. Physiotherapy 1997; 83:375-383.

https://doi.org/10.1016/S0031-9406(05)65791-4

[8]. Walker EM, Openshaw S. Educational needs as perceived by clinical supervisors. Physiotherapy 1994;80:424-431.

https://doi.org/10.1016/S0031-9406(10)60790-0

[9]. Strohschein J, Hagler P, May L. Assessing the need for change in clinical education practices. Phys Ther 2002; 82: 160-170.

https://doi.org/10.1093/ptj/82.2.160

PMid:11856067

[10]. Steward B. The theory/practice divide: bridging the gap in occupational therapy. Br J Occup Ther 1996; 59: 264-268. https://doi.org/10.1177/030802269605900604

[11]. Elnicki DM, Kolarik R, Bardella I. Third-Year medical students' perceptions of effective teaching behaviors in multidisciplinary ambulatory setting. Acad Med 2003; 78(8):815-819.

https://doi.org/10.1097/00001888-200308000-00016 PMid:12915376

[12]. Litzelman DK, Stratos GA, Marriott DJ, Lazaridis EN, Skeff KM. Beneficial and harmful effect of augmented feedback on physicians' clinical teaching performances. Acad Med 1998;73(3):324-332.

https://doi.org/10.1097/00001888-199803000-00022 PMid:9526460

[13]. Maduagwu, Stanley \& Oyeyemi, Adetoyeje \& L, Oyeyemi \& Jasper, Unyime. Perceived importance of clinical teaching attributes among physiotherapy teachers and students. AJHPE 2012;4(1):4-9.

How to cite this article: Omkr Samant, G.D. Vishnu Vardhan. PERCEPTION OF UNDERGRADUATE PHYSIOTHERAPY STUDENTS TOWARDS CLINICAL ATTRIBUTES \& CLINICAL TEACHING. Int J Physiother Res 2020;8(6):3715-3722. DOI: 10.16965/ijpr.2020.185 